\title{
Recurrent cerebral infarction and the antiphospholipid syndrome: effect of intravenous gammaglobulin in a patient with systemic lupus erythematosus
}

\author{
G Sturfelt, F Mousa, H Jonsson, O Nived, H Thysell, F Wollheim
}

\begin{abstract}
A 23 year old woman with systemic lupus erythematosus and antiphospholipid syndrome developed severe thrombocytopenia $\left(5-10 \times 10^{9} / 1\right)$ and cerebral infarction. Treatment with high doses of corticosteroids and cytostatic drugs was not effective. The condition was successfully treated only when three courses of intravenous gammaglobulin at $\mathbf{4 0 0} \mathrm{mg} / \mathrm{kg}$ daily was added. A clear relation was found between the immunoglobulin infusions and rising platelet counts, whereas an effect on the levels of anticardiolipin antibodies could not be recorded. The findings suggested that the mechanisms responsible may be modification and solubilisation of immune complexes or interference with anticardiolipin binding to platelet membranes, or both.
\end{abstract}

High dose intravenous gammaglobulin has been reported to be clinically effective in the treatment of immune complex related disorders, ${ }^{1-3}$ and has been extensively used in cases of idiopathic thrombocytopenic purpura. McVerry et al reported that high dose immunoglobulin infusion had a transient inhibitory effect on lupus anticoagulant ${ }^{4}$; and successful treatment of a woman with lupus anticoagulant and recurrent fetal loss was recently described. ${ }^{5}$ We report a case of antiphospholipid syndrome with thrombocytopenia and cerebral infarctions where this treatment apparently had a beneficial effect.

\section{Methods}

Anticardiolipin antibodies were measured at the National Bacteriological Laboratory, Stockholm, by an enzyme linked immunosorbent assay (ELISA). ${ }^{6}$ The control subjects have been described previously. ${ }^{6}$ The mean +3 SD was chosen as upper level of normal for both IgG and IgM anticardiolipin antibodies, which value corresponded to 3 arbitrary units (U). Lupus anticoagulant was measured at the department of coagulation disorders of Malmö General Hospital, Malmö, Sweden.

\section{Case history}

The patient was a 23 year old woman in whom systemic lupus erythematosus (SLE) was diagnosed in 1984. Her mother had had a cerebral infarction at the age of 30 and a lupus anticoagulant disorder was found but no symptoms or signs of SLE. At the age of 16 the patient manifested transient neurological symptoms with chorea and aphasia, and activated partial thromboplastin time (APTT) was found to be prolonged. The patient had another episode of aphasia in 1984, and dysaesthesia in the right leg. She also developed glomerulonephritis with hypertension, leucopenia, moderate thrombocytopenia $\left(100 \times 10^{9}\right.$ platelets $/ 1$ ), low complement $\mathrm{C} 4$ and $\mathrm{C} 3$ concentrations, and antinuclear antibody and antidouble-stranded DNA tests were positive. Cerebral computed tomography showed a minor cerebral infarction. Serum concentrations of IgG anticardiolipin antibodies were increased ( $>40 \mathrm{U}$, normal $<3 \mathrm{U}$ ), and APTT prolonged (42 s, normal $<35 \mathrm{~s}$ ). An extensive investigation of the coagulation system showed that the patient had normal levels of coagulation factors, but that an anticoagulant was present in the IgG fraction of plasma. She was treated with corticosteroids (prednisolone $5-10 \mathrm{mg} /$ day), azathioprine (200-100 mg/day), low dosage acetylsalicylic acid, and antihypertensive drugs (metoprolol) until the present event.

In June 1988 the patient presented with thrombocytopenia $\left(5-10 \times 10^{9}\right.$ platelets $\left./ 1\right)$, prolonged APTT (134 s), and high concentrations of IgG anticardiolipin antibodies ( $>40 \mathrm{U})$. Bone marrow smears showed the cell morphology to be normal. Treatment with prednisolone (50-100 mg/day) during the following weeks in combination with intermittent oral cyclophosphamide ( $500 \mathrm{mg}$, five courses with one to two week intervals) was unsuccessful. The platelet count remained at $5-20 \times 10^{9} / 1$ and IgG anticardiolipin antibody concentrations high (>40 U). In early August the patient developed an acute stroke with paresis of the right arm. With computed tomography a lacunar infarction was detected in the left hemisphere. The blood pressure was normal $(120 / 70 \mathrm{mmHg}$ ). Echocardiography was normal. The cyclophosphamide was withdrawn, but corticosteroid treatment continued (prednisolone $75 \mathrm{mg} /$ day), now in combination with chlorambucil (4-8 $\mathrm{mg} /$ day) and plasmapheresis. Response was poor, however; the platelet count remained low $\left(10-30 \times 10^{9} / 1\right)$ even after four weeks of treatment, and thus effective anticoagulant treatment still could not be given.

In view of the poor response to the latter regimen it was decided to give a course of intravenous gammaglobulin. At this stage coagulation studies now showed prothrombin 


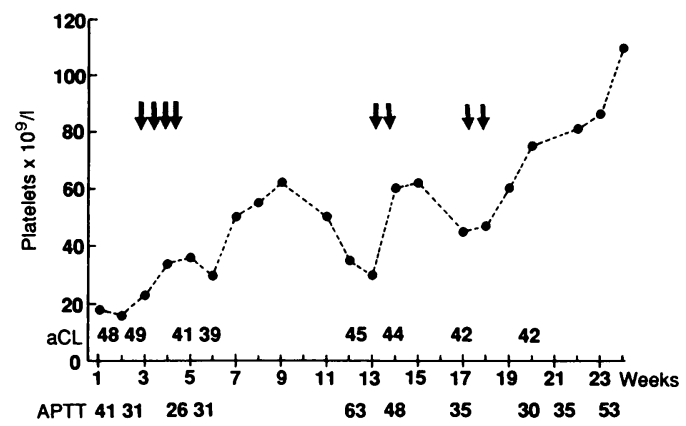

Serial data on a patient with systemic lupus erythematosus and severe antiphospholipid syndrome during treatment with intravenous high dose immunoglobulin. Arrows indicate intravenous immunoglobulin infusions (400 mg/kg). $a C L=$ anticardiolipin antibodies (normal $<3 U$ ); $A P T T=$ activated partial thromboplastin time.

time to be normal, APTT prolonged (4l s), and the IgG anticardiolipin antibody concentration high (49 U) (figure). Treatment with intravenous gammaglobulin at the standard dose of 400 $\mathrm{mg} / \mathrm{kg}$ daily resulted in increasing platelet counts and slightly shorter APTT, though the IgG anticardiolipin antibody concentration was little affected (figure).

One week after the gammaglobulin treatment the patient became febrile and a septic arthritis in the left knee joint was diagnosed. Her condition was further complicated by a venous thrombosis of the left leg, which was treated with heparin infusions for 10 days, followed by low dose heparin given subcutaneously. The chlorambucil treatment was discontinued for 10 weeks during and after the septic infection.

Two further (two day) courses of intravenous gammaglobulin at the same dosage were given with no complications, after which the platelet counts approached $100 \times 10^{9} / 1$. Anticoagulant treatment could now be switched to oral warfarin. The prednisolone dose was gradually reduced to $10 \mathrm{mg} /$ day, and chlorambucil treatment replaced by azathioprine. Renal function remained normal (creatinine-EDTA clearance $105 \mathrm{ml} / \mathrm{min}$ ), and the neurological symptoms remitted. During January to March 1989 her platelet count varied between 90 and $140 \times 10^{9} / 1$, and the IgG anticardiolipin antibody concentrations between 50 and $60 \mathrm{U}$.

\section{Discussion}

This paper describes a patient with active SLE with thrombocytopenia, recurrent cerebral infarction, and renal disease. A favourable outcome was achieved after intravenous gammaglobulin was given in combination with immunosuppressive treatment.

A clear relation was found between the immunoglobulin infusions and rising platelet counts, while an effect on the levels of anticardiolipin antibodies could not be recorded. This argues against an effect of the infusions mediated by anti-idiotypic antibodies present in the therapeutic immunoglobulins. ${ }^{7}$ One possibility is that the immunoglobulins given interfered competitively with the binding of antiphospholipid antibodies to the platelet membrane. Evidence that anticardiolipin anti- bodies bind directly to intact cell membranes is scanty, however. ${ }^{8}$ A contributing factor to the septic complication after the first period of immunoglobulin infusion might have been Fc receptor blockade due to immunoglobulin overload. Interestingly, it has previously been reported that septic conditions in SLE are often related to high amounts of cryoglobulin in serum. ${ }^{9}$ Also, intravenous gammaglobulin might have affected the treatment of autoimmune disease by modification and solubilisation of immune complexes. ${ }^{10} 11$

Severe forms of the antiphospholipid syndrome do occur outside the population with SLE. ${ }^{12-14}$ Since the introduction of sensitive techniques for the detection of anticardiolipin antibodies these disorders have been extensively studied. ${ }^{15}$ Investigations made in epidemiologically retrieved (and therefore probably complete) SLE series have indicated high anticardiolipin antibody concentrations to be a risk factor, primarily for arterial thrombotic disorders. ${ }^{6}$ Cerebral infarction and aseptic endocarditis are typical manifestations of the antiphospholipid syndrome and a high concentration of anticardiolipin antibodies. ${ }^{16-18}$ In this case the patient had had a chorea-like episode several years previously; and the poor prognostic implication of this manifestation in patients with the lupus anticoagulant has been pointed out by Asherson et al. ${ }^{19}$

There is no doubt about the need for new, less risky treatment regimens for use in these disorders. We suggest that the treatment described here might be considered in severe cases of the antiphospholipid syndrome with concomitant thrombocytopenia and thrombotic processes, especially when other active manifestations of SLE are present. Complications following intravenous immunoglobulin infusions are rare, though septic infection may occur. Drawbacks, restricting the use of this treatment to selected and severe cases, are the high cost and the need for intravenous administration.

The study was supported by grants from Konung Gustav V:s 80-års fond, Greta och Johan Kochs stiftelser, Riksförbundet mot reumatism, Alfred Osterlunds Stiftelse, and Förenade Liv Insurance Co.

1 Imbach P, Barandun S, d'Appuzo V, et al. High dose intravenous gammaglobulin for idiopathic thrombocytopenic purpura in childhood. Lancet 1981; i: 1228-31.

2 Pollak S, Cunningham R C, Smithwick E M, Barandun S, Good R A. High dose intravenous gammaglobulin for autoimmune neutropenia. $N$ Engl F Med 1982; 307: 253-5.

3 Pocecco M, Ventura A, Tamaro P, Longo F. High-dose IV IgG in autoimmune haemolytic anemia (Evans syndrome). IgG in autoimmune haemoly

4 McVerry B A, Spaering R, Smith A. SLE anticoagulant: transient inhibition by high dose immunoglobulin infusions. transient inhibition by high dose im.

5 Carreras L O, Perez G N, Vega H R, Casavilla F. Lupus Carreras L O, Perez G N, Vega H R, Casavilla F. Lupus
anticoagulant and recurrent fetal loss: successful treatment with gammaglobulin. Lancet 1988; ii: $393-4$.

6 Sturfelt G, Nived O, Norberg R, Thorstensson R, Krook K. Anticardiolipin antibodies in patients with systemic lupus erythematosus. Arthritis Rheum 1987; 30: 382-8.

7 Sultan Y, Kazatchkine M D, Maisonneuve P, Nydegger U E Anti-idiotypic suppression of autoantibodies to factor VII (antihaemophilic factor) by high-dose intravenous gammaglobulin. Lancet 1984; ii: 765-8.

8 Norberg R, Ernerudh J, Hamsten A, Unander A M Årfors L. Phospholipid antibodies in cardiovascular disease Acta Med Scand 1987; 221 (suppl 715): 93-8.

9 Nived O, Sturfelt G, Wollheim F. Infection in systemic lupus erythematosus: a controlled study including an epidemiological group. $Q \mathcal{J}$ Med (New series 1985; 55: 271-87. 
10 Lin $R$ Y, Racis S P. In vivo reduction of circulating Clq binding immune complexes by intravenous gammaglobulin administration. Int Arch Allergy Appl Immunol 1986; 79; 286-90.

11 Sato M, Kohjima H, Koshikawa S. Modification of immune complexes deposited in tissue sections treated with
sulfonized gammaglobulin. Clin Exp Immunol 1986; 64: sulfonized

12 Segovia D A, Sanchez-Guerrero J. Primary antiphospholipid syndrome. F Rheumatol 1989; 16: 482-8.

13 Mackworth-Young C G, Loizou S, Walport M J. Primary antiphospholipid syndrome: features of patients with raised antiphospholipid syndrome: features of patients with raised Rheum Dis 1989; 48: 362-7.

14 Asherson R A. A "primary" antiphospholipid syndrome. f Rheumatol 1988; 15: 1742-6.
15 Hughes G R V, Harris E N, Gharavi A E. The anticardiolipin syndrome. $\mathcal{F}$ Rheumatol 1986; 13: 486-9.

16 Levine S R, Welch K M A. The spectrum of neurological disease associated with antiphospholipid syndrome. Arch Neurol 1987; 44: 876-83.

17 Asherson R A, Khamashta M A, Antonio G, et al. Cerebrovascular disease and antiphospholipid antibodies in systemic lupus erythematosus, lupus-like disease, and the primary antiphospholipid syndrome. Am J Med 1989; 86:

18 Ford P M, Ford S A, Lillicrap D P. Association of lupus anticoagulant with severe valvular heart disease in systemic lupus erythematosus. $\mathcal{F}$ R heumatol 1988; 15: 597-600.

19 Asherson R A, Derkson R H W M, Harris E N, et al. Chorea in systemic lupus erythematosus and 'lupus-like disease". Association with antiphospholipid antibodies. Semin Arthritis Rheum 1987; 16: 253-9. 